Meta

Journal des traducteurs

Translators' Journal

\title{
La intertextualidad en el derecho y en la lingüística. La intertextualidad entre los documentos jurídicos de una cadena. Un análisis para la traducción
}

\section{Elena Ferran}

Volume 50, numéro 4, décembre 2005

Pour une traductologie proactive - Actes

For a Proactive Translatology — Proceedings

Por una traductología proactiva - Actas

URI : https://id.erudit.org/iderudit/019836ar

DOI : https://doi.org/10.7202/019836ar

Aller au sommaire du numéro

Éditeur(s)

Les Presses de l'Université de Montréal

ISSN

0026-0452 (imprimé)

1492-1421 (numérique)

Découvrir la revue

Citer cet article

Ferran, E. (2005). La intertextualidad en el derecho y en la lingüística. La intertextualidad entre los documentos jurídicos de una cadena. Un análisis para la traducción. Meta, 50(4). https://doi.org/10.7202/019836ar

\section{Résumé de l'article}

Le traducteur juridique de documents privés s'intéresse au contexte documentaire du document d'origine et, plus notamment, aux renvois implicites ou explicites que celui-ci fait à d'autres documents, de telle façon qu'une chaîne de documents est créée dont l'un des documents est central ou de base par rapport aux autres qui sont subordonnés. Cet article analyse les chaînes de documents associés entre eux appartenant à la même circonstance d'émission prévue par le système juridique qui établit les conditions documentaires requises pour la validité du negotium.

L'exercice que l'on propose consiste à reconnaître les conditions de validité du negotium requises dans le document de base qui est associé aux documents subordonnées en tant que guide du traducteur dans sa lecture afin qu'il découvre graduellement les éléments du negotium dans le texte, soient explicites ou implicites. 


\title{
La intertextualidad en el derecho y en la lingüística. La intertextualidad entre los documentos jurídicos de una cadena. Un análisis para la traducción
}

\author{
ELENA FERRAN \\ Universitat Poтpeu Fabra, Barcelona, España \\ elena.ferran@upf.edu
}

\begin{abstract}
RÉSUMÉ
Le traducteur juridique de documents privés s'intéresse au contexte documentaire du document d'origine et, plus notamment, aux renvois implicites ou explicites que celui-ci fait à d'autres documents, de telle façon qu'une chaîne de documents est créée dont l'un des documents est central ou de base par rapport aux autres qui sont subordonnés. Cet article analyse les chaînes de documents associés entre eux appartenant à la même circonstance d'émission prévue par le système juridique qui établit les conditions documentaires requises pour la validité du negotium.

L'exercice que l'on propose consiste à reconnaître les conditions de validité du negotium requises dans le document de base qui est associé aux documents subordonnées en tant que guide du traducteur dans sa lecture afin qu'il découvre graduellement les éléments du negotium dans le texte, soient explicites ou implicites.
\end{abstract}

\begin{abstract}
The legal translator of private documents is interested in the documentary context of the ST and, more specifically, in the tacit or express remission to other documents, creating therefore, a chain of documents, where one of them is central and basic as opposed to the others, the subordinate ones. This paper particularly deals with the group or chain of documents, related because they belong to the same circumstance of issue as regulated by the legal systems, which set out the documentary requirements necessary for the existence of the basic document.

We put forward an exercise for the translator: he is to recognise the requirements for the existence of the negotium within the basic document since they are associated with subordinate documents as a guide for him while reading in order that he gradually finds out about the explicit or implicit elements of the negotium.
\end{abstract}

\section{MOTS-CLÉS/KEYWORDS}

legal document, intertextuality, translation, transcription, remission, documentary context, chain of documents.

Al traductor jurídico de documentos privados le interesa el contexto documental del documento de partida y, más específicamente, la remisión implícita o explícita a otros documentos, creándose con ello una cadena de documentos, donde uno de los documentos es central o básico respecto de los otros, subordinados.

Tratamos de una manifestación importante del concepto de intertextualidad: aquella que se da en los grupos o cadenas de documentos relacionados por pertenecer a una misma circunstancia de emisión regulada por el ordenamiento jurídico. Este concepto nos enfrenta a otros conceptos como documento básico/subordinado, por una parte, y negocio causal/negocio abstracto, por otra.

Nos centramos en la remisión que un documento básico (contrato o testamento) hace a otros que se le subordinan, en cumplimiento de los requisitos de validez del negocio básico. El ejercicio que proponemos, consistente en reconocer los requisitos de validez del negocio en el seno del documento básico en su relación con los documentos subordinados guía al traductor en su lectura para que descubra gradualmente los elementos del negocio en tanto que explícitos o 
implícitos en el texto: primero los sujetos otorgantes, después el acto realizado con consentimiento sobre el objeto y la causa del contrato y, finalmente, las consecuencias jurídicas presentes y futuras del mismo. Al paso que el lector realiza esa secuencia topa con los lazos de remisión del negocio a los documentos relacionados que encarnan y explican los mencionados requisitos de validez.

\section{Motivación}

En la práctica de la traducción jurídica, en ocasiones, el encargo de traducción es múltiple: se encarga simultáneamente al traductor la traducción de varios documentos relacionados entre sí de forma próxima o remota. La relación es próxima si la conexión entre los documentos deriva de un mismo contexto comunicativo negocial (o supuesto de hecho) contemplado por la ley. La relación es remota, si la conexión entre los documentos obedece a una situación comunicativa casual: los documentos han entrado en relación por avatares de la vida no previsibles ni pautados por la norma jurídica. Nos interesa el primer supuesto, más habitual. Por ejemplo, en un pleito de reclamación de cantidad se presentan como pruebas del derecho de crédito, no sólo el contrato, sino toda la documentación preparatoria previa al mismo, y, sobre todo, toda la documentación que guarda relación con el cumplimiento o incumplimiento del mismo: talones y otros medios de pago, cartas de reclamación, requerimientos notariales de pago, etc. Es interesante establecer estrategias de traducción para este caso que consigan un criterio unitario.

Aun en el caso de que el encargo de traducción se refiera a un único documento, éste se inscribe en un conjunto de documentos con los que guarda relación y cuyo contenido mínimo, en cuanto le permite al traductor entender el documento que tiene en las manos, infiere gracias a su conocimiento, precisamente, de la relación de intertextualidad que se establece entre ese documento y todos los que relacionen con él.

La observación de los nexos de remisión entre el documento y otros que constituyen requisitos previos para su validez jurídica (situación jurídica previa), puede servir para esbozar un método de lectura fundamentado en la secuencia de conceptos (sujeto agente-sujeto receptor; acto jurídico (consentimiento que versa sobre el objeto y la causa del contrato); las circunstancias y consecuencias jurídicas del acto que se realiza), que nos permiten categorizar los documentos de la cadena, según veremos.

Esta realidad sociológica del encargo múltiple fue el punto de partida que estimuló en un comienzo la reflexión teórica que sigue, pero descubrimos al tiempo que analizar el contexto documental del documento llevaba a repasar los elementos del negocio en el seno del documento, facilitando y organizando con ello la misma lectura, que se veía pautada y ayudada por los hitos de remisión documental, a modo de recordatorios de ese eje nuclear constituido por los elementos o requisitos del negocio.

\section{Conceptos previos}

El acto jurídico se realiza en un marco o situación jurídica previa en que se encuentran el otorgante u otorgantes del negocio con la intención de modificarla y producir una nueva situación jurídica resultante.

Fuerza ilocutiva $\quad$ Efecto perlocutivo

\begin{tabular}{|l|l|l|}
\hline $\begin{array}{l}\text { Situación } \\
\text { Jurídica } \\
\text { Previa }\end{array}$ & $\begin{array}{l}\text { Acto jurídico } \\
\text { (macroacto de habla) }\end{array}$ & $\begin{array}{l}\text { Situación jurídica } \\
\text { Resultante }\end{array}$ \\
& $\begin{array}{l}\text { Sujeto } \\
\text { Acto jurídico, etc. }\end{array}$ & \\
\hline
\end{tabular}


Así, el vendedor es propietario del inmueble (situación jurídica previa). Desea venderlo y otorga un contrato de compraventa con los correspondientes derechos y obligaciones de entrega de la cosa y pago del precio que desembocan en la transmisión de la propiedad sobre el inmueble (situación jurídica resultante)

Como la transmisión de la propiedad no se produce en un instante, sino que es necesario un tiempo para la formación del consentimiento y el otorgamiento y eficacia del acto, de ahí que se diga que los otorgantes del acto/documento establecen una relación jurídica negocial que tiene tres estadios cronológicos que conforman su vida: primerro, la formación del consentimiento; segundo, el otorgamiento del acto propiamente dicho, que se inscribe en la situación jurídica previa y, finalmente, el cumplimiento y ejecución de lo derechos y obligaciones derivados del acto, que crearán una nueva situación jurídica (la situación jurídica resultante).

\begin{tabular}{|l|l|l|}
\hline $\begin{array}{l}\text { Formación del consentimiento o } \\
\text { voluntad (actos preparatorios) }\end{array}$ & $\begin{array}{l}\text { Acto de Otorgamiento } \\
\text { del } \\
\text { DOCUMENTO }\end{array}$ & $\begin{array}{l}\text { Actos de cumplimiento } \\
\text { (ejecución voluntaria o } \\
\text { forzosa) }\end{array}$ \\
\hline
\end{tabular}

Estos esquemas nos devuelven a una clasificación fundamental: los documentos anteriores y los posteriores a otro básico con el que se relacionan. El documento anterior suele ser preparación, condición o requisito legal para que se produzca el otro y forma parte de la situación jurídica previa. Incluso en los supuestos en que no se deba otorgar por ley, favorece la preparación del documento posterior. Por otra parte, el documento posterior normalmente se produce en ejecución del documento jurídico básico y es parte de la situación jurídica resultante. En ocasiones, debe realizarse por ley (como el pago de impuestos) y en otras es conveniencia del sujeto receptor del derecho realizarlo (la inscripción de una escritura de compraventa de inmueble en el registro de la propiedad).

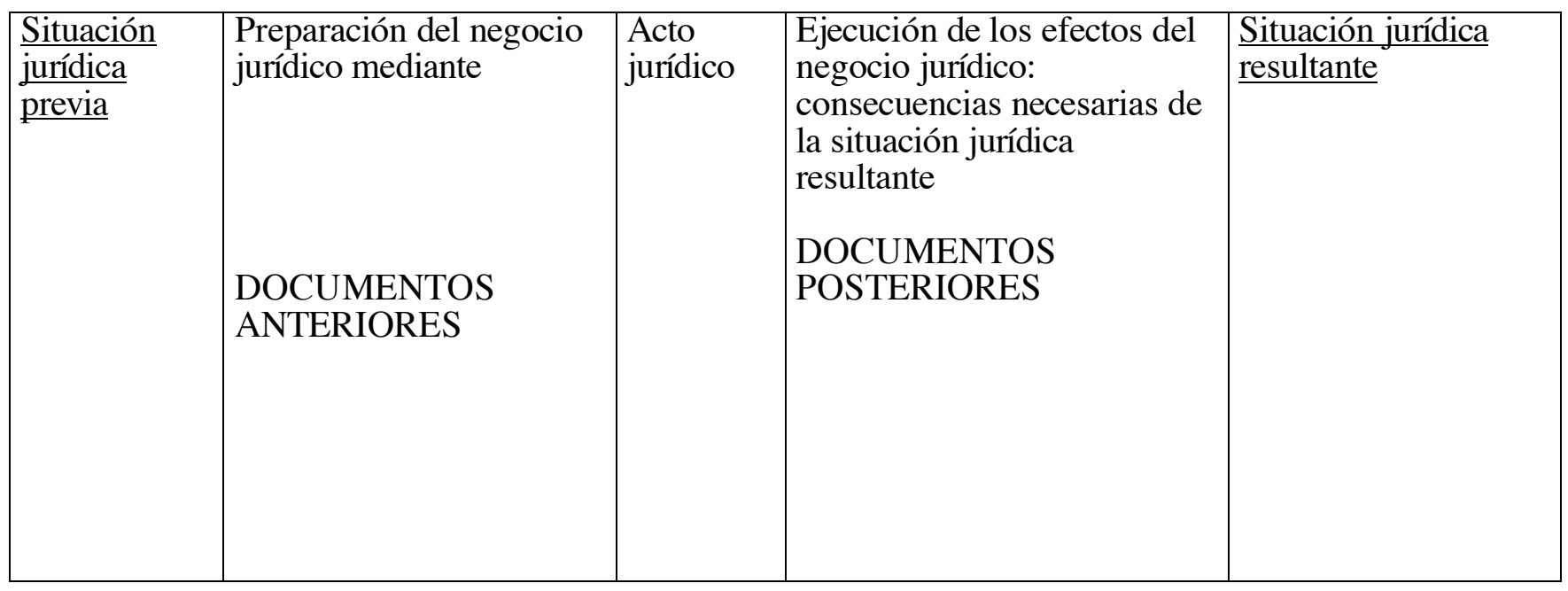


El esquema anterior gira en torno al acto jurídico: lo presenta como modificador de una situación jurídica previa y causante de una situación jurídica resultante y nos permite comprender ambas situaciones como generadoras de documentos jurídicos

Nos centraremos en un ejemplo concreto: en la relación y remisión del documento negocial testamento o contrato a otros documentos para con ello cumplir con los requisitos de validez del negocio en tanto que dicha relación se convierte en un elemento de interpretación y traducción para el traductor.

El estudio de la intertextualidad entre los documentos del grupo permite comprender el documento de partida en su contexto comunicativo documental. Ese contexto comunicativo documental inunda de sentido el texto y lo contextualiza al proporcionarle un contexto prototípico. Sin embargo, como tal documento que es, en tanto que unidad textual y unidad de sentido, el documento es perfectamente inteligible sin necesidad de leer los documentos relacionados con el mismo. Precisamente, la existencia del documento relacionado es un sobreentendido, una implicatura que el lector hace con facilidad gracias a la remisión o lazo de unos conceptos jurídicos a otros, de unos documentos a otros, a la luz del ordenamiento jurídico.

El lector comprende el documento básico (la compraventa) porque conoce su estructura esencial. El hecho de que dicha estructura esencial esté ligada a los documentos "relacionados" (la letra de cambio que se emite para pago del precio de la compraventa) y a su estructura intertextual, no le resta autonomía como documento.

Distinguimos, por tanto, entre documentos básicos (el testamento, el contrato, la ley, la sentencia, etc. ${ }^{\top}$, y los documentos subordinados a otro básico (Cornu: 2000), que se encaminan al otorgamiento del negocio básico o son una consecuencia del mismo. Así, estos documentos subordinados (normalmente meras declaraciones de voluntad) pueden ser anteriores o posteriores al documento básico. Si son anteriores, normalmente tienen la función de preparar para el otorgamiento del documento básico. Los posteriores normalmente se otorgan en ejecución del básico, aunque puedan también tener otras funciones. ${ }^{2}$

En el ámbito del derecho contractual observamos una concatenación de negocios. Así, por ejemplo, la oferta y la aceptación son documentos previos al otorgamiento del contrato. La promesa de contrato obliga a la conclusión de un contrato posterior. Otros, por el contrario, son posteriores. Así, un contrato da lugar a otros documentos posteriores: un documento de carta de pago, otro de reconocimiento de deuda, otro de renuncia de derecho, un título valor (una letra de cambio o un pagaré, que se emiten para pago del precio de la compraventa), etc. Lo cierto es que, anteriores o posteriores al negocio básico, se producen en un orden cronológico determinado. Igualmente, en el ámbito procesal, por ejemplo, la citación de un litigante produce el efecto procesal de legitimar su comparecencia (o su declaración en rebeldía, si ésta no se produce) y otros actos procesales posteriores que culminarán en el pronunciamiento de la sentencia. Por eso en el ámbito procesal se habla del procedimiento, que consiste en una serie de actos que desembocan en un acto final.

\section{La independencia: negocios causales y negocios abstractos}

Veamos en qué consiste la dependencia entre documentos jurídicos. En los ejemplos descritos uno de los documentos jurídicos, el subordinado, depende del anterior o posterior porque en él encuentra su causa (negocio causal, aunque al mismo tiempo tenga una entidad propia desde el punto de vista textual. Sean anteriores (preparatorios) o posteriores (ejecutivos), todos ellos encuentran su razón de ser, su "causa" en el negocio básico causal.

En principio, todos los negocios son causales o causados. Excepcionalmente, sin embargo, si el negocio posterior es abstracto, el derecho presume y finge que no ha sido causado por un negocio anterior, sino que tiene una independencia y autosuficiencia incluso negocial, aunque tenga su origen en un negocio anterior" (Uría 1995). Se lo califica como "título valor" (negotiable instrument). Es el caso de la letra de cambio, por ejemplo. La diferenciación entre negocio causal y 
abstracto es importante porque tiene consecuencias lingüísticas. La dependencia causal se manifiesta en una remisión expresa o tácita al negocio previo. Por el contrario, en el caso de los negocios abstractos, aunque encuentren su causa y origen también en un negocio previo, tratan de distanciarse del mismo y no aparece dicha remisión. Esa es precisamente su función: servir en el tráfico independientemente del negocio que les dio origen. ${ }^{5}$ Dicha independencia tiene la contrapartida de buscar por otros medios la seguridad jurídica que se pierde desligando al negocio abstracto del causal. Así, los títulos valores suelen ser títulos ejecutivos. ${ }^{6}$

Por supuesto, el negocio abstracto participa también de ese modelo de razonamiento jurídico que postulamos que es uniforme como expresión de la autonomía de la voluntad cuando hablamos de un discurso jurídico negocial común, deglosable en sintagmas de eficacia según el esquema agente, acto, objeto, receptor del acto y circunstancias del acto.

"Por esta letra de cambio/ pagará/ Vd/ al vencimiento expresado/ la cantidad de , en el domicilio de pago siguiente ".

Las características específicas del negocio abstracto, exigencias de seguridad jurídica, flexibilidad y rapidez de funcionamiento en el comercio, dotan al discurso que contiene de unas características especiales de concisión y precisión y su lenguaje está sumamente estandarizado por dos razones: por la mencionada independencia respecto del negocio causal previo y también en aras de la seguridad jurídica. En un título valor, más que oraciones hilvanadas, sólo existen menciones diversas muy concisas que no dan pábulo a una interpretación extensiva, sino estricta o literal, en sus justos términos. Cuando hablamos de interpretación literal no estamos diciendo que estemos renunciando al principio general que determina una interpretación teleológica, sino que, en este caso, en este tipo de documento, el sentido del documento está perfectamente delimitado por la propia ley.

Veamos una letra de cambio:

\begin{tabular}{|ll|}
\hline Lugar de libramiento & Importe \\
Fecha de libramiento & Vencimiento \\
Por esta letra de cambio pagará $V d$. & \\
Al vencimiento expresado la cantidad de_ \\
en el domicilio de pago siguiente \\
PERSONA O ENTIDAD \\
DIRECCIÓN \\
CLÁUSULAS \\
NOMBRE Y DOMICILIO DEL LIBRADO FIRMA NOMBRE Y DOMICILIO DEL \\
LIBRADOR \\
ACEPTANTE
\end{tabular}

En el documento de la letra vemos menciones de los distintos elementos de la obligación, y los actos jurídicos correspondientes. El acto de emisión (el libramiento) no aparece como tal, sino que ha dejado rastro en las distintas menciones (fecha de libramiento, lugar de libramiento, librador, librado-aceptante). El performativo (en negrita) sólo aparece en la expresión: "Por esta letra de cambio pagará Vd., al vencimiento expresado, la cantidad de _, en el domicilio siguiente.” Sin duda, la obligación de pago que emana de la letra de cambio necesariamente debe formularse de forma expresa y no de forma implícita, mediante simples menciones. 
En resumen, donde hay causalidad, hay remisión tácita o explícita de un documento a otro dentro de la cadena de documentos y, en todo caso, de ésta y de cada uno de sus elementos al ordenamiento jurídico y a la ley de forma genérica, en tanto que causa primigenia de todo documento jurídico y de toda cadena de documentos. Sólo así podremos enmarcar convenientemente el estudio de lo que hemos denominado "la cadena de documentos" de cara a la traducción.

\section{\begin{tabular}{|c|c|}
\hline Los actos anteriores y posteriores. Los poderes \\
\hline
\end{tabular}}

Para entender la intertextualidad documental descrita, en tanto que contexto comunicativo del documento, vamos a explorar supuestos concretos, a saber, el contrato y el testamento, en su remisión a otros documentos. Los requisitos de validez de estos negocios se relacionan con actos anteriores y posteriores que se formalizan mediante documento..

Tomemos como primer ejemplo el testamento. La situación jurídica previa en el caso del testamento se caracteriza por un deseo de testar que puede que se plasme en la remisión a documentos jurídicos previos para acreditar la capacidad o titularidad sobre los bienes, pero no es lo habitual. Por el contrario, existen documentos ejecutivos del testamento que procuran su efectividad. Así, la transmisión hereditaria es complicada y necesariamente conlleva un procedimiento de autenticación o validación del testamento que, en el caso anglosajón, cobra la forma de probate proceedings y en el caso español se concreta en la aceptación de la herencia ante Notario, (previo certificado del testamento expedido por el Registro de Ultimas Voluntades) y la consiguiente distribución de los bienes entre los herederos a cargo del albacea.

\begin{tabular}{|l|l|l|l|l|}
\hline $\begin{array}{l}\text { ACTOS } \\
\text { ANTERIORES }\end{array}$ & $\begin{array}{l}\text { Situación } \\
\text { jurídica previa }\end{array}$ & $\begin{array}{l}\text { Acto jurídico } \\
\text { Deseo de testar } \\
\text { Capacidad para } \\
\text { testar (más de 14 } \\
\text { años), etc. }\end{array}$ & $\begin{array}{l}\text { Otorgamiento del jurídica } \\
\text { testamento }\end{array}$ & $\begin{array}{l}\text { ACTOS } \\
\text { Pelación en el } \\
\text { Pomento del } \\
\text { fallecimiento }\end{array}$ \\
\hline
\end{tabular}

Estos son los documentos posteriores al otorgamiento por razón de la delación (por orden cronológico), según el derecho español.

\begin{tabular}{|l|l|l|}
\hline $\begin{array}{l}\text { 1.- Aceptación del } \\
\text { nombramiento por el } \\
\text { albacea (tácita o } \\
\text { documental) }\end{array}$ & $\begin{array}{l}\text { 2. Escritura de } \\
\text { adjudicación y } \\
\text { manifestación de herencia } \\
=\text { Aceptación de los } \\
\text { herederos }\end{array}$ & $\begin{array}{l}\text { 3.-Liquidación del impuesto } \\
\text { de sucesiones }\end{array}$ \\
\hline $\begin{array}{l}\text { 4.- Inscripción de la } \\
\text { transmisión de } \\
\text { inmuebles en el } \\
\begin{array}{l}\text { Registro de la } \\
\text { Propiedad }\end{array}\end{array}$ & & \\
\hline
\end{tabular}

Igualmente el contrato responde al esquema mencionado. Distinguimos entre los contratos de colaboración y los dispositivos. 


\begin{tabular}{|l|l|l|}
\hline Situación jurídica previa: & $\begin{array}{l}\text { Otorgamiento del acto } \\
\text { jurídico : }\end{array}$ & $\begin{array}{l}\text { Situación jurídica resultante : } \\
\text { Deseo de llegar a un } \\
\begin{array}{l}\text { acuerdo + oferta y } \\
\text { aceptación (...) }\end{array}\end{array}$ \\
\hline
\end{tabular}

Distingamos la preparación del negocio de su ejecución:

A) Durante el periodo preparatorio del contrato también se aportan las pruebas o documentos acreditativos de los elementos o requisitos del contrato que son también previos al mismo. Recordemos que los elementos del contrato son el consentimiento (el acto), el objeto y la causa (Art. 1261 del Código Civil Español) y se prueban documentalmente de la siguiente forma:

En cuanto al consentimiento y la capacidad de las partes, el consentimiento manifestado se presume y no es necesario acreditarlo, pero la capacidad, normalmente, es necesario acreditarla, como también la personalidad jurídica. De ahí que se produzca entonces una remisión a documentos previos (poderes de representación, el Acta de Constitución de la Sociedad que contrata, el Documento Nacional de Identidad del otorgante, etc.). Sin embargo, el consentimiento es el resultado de un proceso que culmina en la oferta y aceptación definitivas. Y para que eso suceda es necesario que se produzcan unos tanteos previos que tienen forma documental.

Los actos preparatorios del contrato en el caso de la compraventa son los tanteos previos necesarios para la formación del consentimiento contractual. Durante la fase de negociaciones (bargaining), las partes formulan ofertas y contraofertas recíprocas que acaban en una oferta y aceptación definitivas. Pues bien, ese tanteo es largo y se concreta en innumerables documentos: envío de la lista de precios, envío de muestras, negociación de un descuento por pronto pago, consultas al banco para posible crédito. Todos estos actos guardan una relación con el otorgamiento y eficacia jurídica del contrato futuro y son una exigencia de la naturaleza de las cosas, no tanto de la ley, que no se ha preocupado por regular algo que se produce naturalmente en la práctica sin su intervención. Pues bien, todos esos actos previos se plasman en documentos relacionados con la compraventa que se hará. ${ }^{8}$

Así, la oferta, tal y como se presenta en el Código Civil Español, es el resultado de una correspondencia previa entre las partes, que puede ser relativamente larga.

"El consentimiento se manifiesta por el concurso de la oferta y la aceptación sobre la cosa y la causa que han de constituir el contrato. La aceptación hecha por carta no obliga al que hizo la oferta sino desde que llegó a su conocimiento. El contrato, en tal caso, se presume celebrado en el lugar en que se hizo la oferta." (Art. 1262 Sec 1", Cap IV)

La regulación del Código Civil español se supedita a cualquier regulación legal más específica en la materia. Así, para la compraventa mercantil rige el Código de Comercio Español y cualquier norma internacional de aplicación directa en España; así, por ejemplo, la Convención Internacional de Viena de Compraventa de Mercaderías (1979), que, por su parte, regula con más detalle la oferta y la aceptación (artículos 12 y siguientes). Sin embargo, tampoco la Convención denomina la retahíla 
de documentos que plasman la interacción entre comprador y vendedor para la formación del consentimiento. En ausencia de regulación legal es entonces el uso mercantil el que se encarga de denominar dichos documentos: letters of enquiry (solicitud de información), cursadas por el comprador quien asks for quotations (cotizaciones de precios). Recibe entonces el comprador la información por parte del vendedor de una forma más o menos elaborada: puede que incluso reciba ya las conciones (terms and conditions) del futuro contrato redactados de forma detallada para propiciar un contrato de adhesión, es decir, para imponer sus condiciones al futuro comprador. ${ }^{9}$

Por fin se produce la aceptación que, igualmente, en el tráfico comercial no suele denominarse como tal. Por el contrario, suele suceder que el comprador.

"sends a Purchase order to the seller. The offeree checks material terms; price, quantity, date of delivery, and payment terms. If it agrees to the terms, offeree responds with its prepared form; e.g. Seller sends Acknowledgment to Buyer. ${ }^{10}$ " (Burnham 1993: \&1.4.3.).

En segundo lugar, el objeto debe ser lícito (conforme a las reglamentaciones de sanidad, por ejemplo, en el caso de las mercancías) y el título sobre el objeto debe estar en toda regla (good title/título legítimo). Suele acreditarse la bondad del título y también que las mercaderías, por ejemplo, tienen las características adecuadas mediante muestras y, ya en el texto del contrato, mediante la consiguiente cláusula de warranties (fit and in good condition). Se produce entonces una remisión al título de propiedad y a las muestras o documentación, que permiten especificar y describir las mercancías.

En tercer lugar, la causa (adequate consideration) se presume, no es necesario acreditarla, si bien en los contratos anglosajones su mención ${ }^{11}$ (que no su acreditación documental) es obligada por medio de una cláusula de estilo.

Transfer of Ownership. The Grantor grants and conveys (transfers ownership of) the property described below to the Grantee. This transfer is made for the sum of $(\$ 1.00)$

ONE 00/100-----------DOLLAR

The Grantor acknowledges receipt of this money.

En este ejemplo, incluso, la contraprestación (consideration) es virtual (de un dólar), es decir, no existe realmente una contrapartida. El documento de deed en este caso servía para que el albacea testamentario adjudicara los bienes de la herencia.

En la compraventa española de inmuebles ante Notario Español (compraventa de bienes radicados en España) también es corriente incluir una cláusula de estilo que alude al precio pagado por adelantado:

"El comprador declara que ha pagado el precio por adelantado por medio de talón (...), sirviendo la presente escritura notarial como formal carta de pago del mismo"

con lo que se alude a un documento previo probatorio no sólo de "la causa", sino también del cumplimiento de una de las obligaciones principales de la compraventa, el pago del precio. Además, es un requisito necesario en el supuesto de reserva de dominio para que se produzca la finalidad principal del contrato: la transmisión de la propiedad. 
b) En cuanto a los documentos posteriores, como son dos las obligaciones esenciales de la compraventa: (la obligación de pago del precio y la obligación de entrega de la mercancía) clasificamos los documentos posteriores a la compraventa según ese criterio, pues necesariamente se refieren al cumplimiento de una de las dos obligaciones.

\begin{tabular}{|l|l|l|}
\hline $\begin{array}{l}\text { ACTOS POSTERIORES: } \\
\text { CUMPLIMIENTO DEL } \\
\text { CONTRATO }\end{array}$ & \\
\hline En relación con el precio & $\begin{array}{l}\text { En relación con la entrega de la } \\
\text { mercancía/inmueble }\end{array}$ & \\
\hline $\begin{array}{l}\text { Carta de pago del precio o, por } \\
\text { contra, si el pago está aplazado, los } \\
\text { pagarés, letras de cambio, cheques, } \\
\text { etc. que incorporan la promesa de } \\
\text { pago consiguiente. }\end{array}$ & $\begin{array}{l}\text { Resguardo de depósito de la } \\
\text { mercancía. }\end{array}$ & Albarán de entrega de la mercancía. \\
$\begin{array}{l}\text { Crédito documentario y los títulos } \\
\text { que se emitan en ejecución del } \\
\text { mismo. }\end{array}$ & Conocimiento de embarque, etc. & \\
\hline
\end{tabular}

Si nos centramos en los documentos relativos a la entrega de la mercancía, observamos que se trata de documentos que constituyen una notificación de las personas que gestionan las mercancías en los distintos momentos: Así, el vendedor, en un primer momento, envía al comprador un advice note: aviso de expedición (o nota de envío)/nota de confirmación/nota de consignación). Según Lozano Irueste (2001), ya en el momento de la entrega de la mercancía se produce otro documento: Delivery note: nota de entrega/albarán de entrega. En ocasiones el comprador emite un acknowlegment of receipt, que básicamente tiene la misma función que el albarán de entrega. Igualmente, el transporte de la mercancía determina la emisión de un documento que, además, constituye un título valor: conocimiento de embarque/bill of lading (en el transporte marítimo), el conocimiento de embarque aéreo/airway bill (en el transporte aéreo). Por otra parte, los documentos relativos a la obligación de pago del precio son, por ejemplo, los siguientes: Invoicelfactura; pro-forma invoicelfactura proforma; statement of account/estado de cuentas; debit and credit notes/nota de débito y crédito; demand notelpagaré a la vista; letter of credit/carta de crédito o crédito documentario.

Creemos que los ejemplos anteriores sirven para poner de manifiesto la profusión de documentos, tanto durante la fase de formación del consentimiento contractual, como durante la fase de ejecución del contrato.

La observación de la cadena de actos jurídicos relacionados nos permite entender mejor el acto de remisión de un documento a otro u otros y puede servir de base para un estudio posterior sobre la relación e interpenetración que existe entre el léxico y tejido discursivo empleado en los mismos.

Veamos a continuación las remisiones en el seno de un contrato de disponibilidad crediticia, emitido en el contexto de una compraventa internacional de mercaderías. En virtud de este documento, el prestatario acepta las condiciones desorbitadas que le impone el prestamista; se produce un contrato de adhesión. Encontramos indicios de que es el propio banco quien propone el redactado de las cláusulas de la solicitud en el hecho de que las cláusulas son más gravosas para el prestatario beneficiario del crédito que para el banco prestamista. A excepción de la obligación fundamental de proporcionar la disponibilidad crediticia a cambio de una comisión de disponibilidad, el resto de las cláusulas supone obligaciones o limitaciones para el prestatario. 
Efectivamente, aunque el documento aparece como un formulario bancario que consiste en una carta de solicitud de línea crediticia que presenta el cliente al banco, lo cierto es que la solicitud ha sido redactada por el propio banco e incorpora todas las cláusulas típicas de un contrato de este tipo. Veamos cómo se produce la aparición de los documentos relacionados en el documento: la sola lectura de las tres primeras cláusulas del contrato ya nos da idea de que el negocio jurídico básico (contrato de disponibilidad crediticia) se remite a otros negocios relacionados que, en este caso, garantizan el cumplimiento de las obligaciones respectivas de las partes. Así, la obligación de proporcionar una disponibilidad crediticia por parte del banco se instrumenta por medio de una carta de crédito documentario. Por otra parte, la obligación de pago de la comisión de disponibilidad (la contraprestación por los intereses) también se garantiza mediante la emisión de un pagaré:

"We shall, upon your request, following any such disbursement, execute and deliver to you a promissory note embodying the foregoing terms."

Veamos el comienzo de la carta de crédito. Hemos subrayado los documentos relacionados.

AGREEMENT

(STANDBY LETTERS OF CREDIT)

RAINER NATIONAL BANK

To WORLD BANKING DIVISION T22-1

P.O. Box 3944

Seattle, Washington 98124

Gentlemen:

We hereby apply to you for a loan in the principal amount of "Eighty Five Thousand and 00/100_DOLLARS (85,000) subject to the following terms and conditions: (If standby letter of credit is issued in a foreign currency the principal of the loan will be the U.S dollar equivalent of the foreign currency amount, converted at the rate of exchange on the date of payment.)

1.- $\quad$ The loan shall be disbursed only by means of drawings under the Letter of Credit for which application appear on the reverse hereof.

2.- $\quad$ Each advance ${ }^{12}$ which is disbursed as provided in Paragraph 1 shall bear interest payable monthly at a rate per annum Prime +2.00 per cent $(P+2 \%)$ in excess of your Bank's Large Business Prime Rate (the "Prime Rate") from time to time established by the Bank as in effect at the time of disbursement and shall mature On Demand days from the date of the loan. We shall, upon your request, following any such disbursement, execute and deliver to you a promissory note embodying the foregoing terms. (...)

\section{La remisión}

Una vez estudiado el fenómeno de la cadena cronológica de documentos relacionados, nos dirigimos ya al acto/documento de otorgamiento (documento básico), a sus requisitos de validez y a las remisiones que éste pueda hacer a los actos anteriores o posteriores (documentos relacionados) en cumplimiento de algunos requisitos legales. En consecuencia, estudiamos el acto de remisión en 
tanto que permite interpretar el documento origen (contrato o testamento) en relación con los que le rodean, y también a fin de preparar para la traducción del propio nexo de remisión, una vez entendida su función pragmático-jurídica.

En principio, la remisión intertextual en el derecho evita tener que transcribir un documento relevante en su integridad. Un documento es relevante porque cumple una función jurídica determinada en el documento básico. La función jurídica, por ejemplo, es acreditar que se cumple un requisito de capacidad del otorgante, es decier, de explicar por qué tienen esa capacidad con todo el detalle del apoderamiento pero sin reproducir el contenido de todo el documento y simplemente se hace una referencia aunque el documento es relevante en toda su extensión. ${ }^{13} \mathrm{Si}$ se transcribe sólo una parte es porque unas porciones se pueden extraer del conjunto precisamente porque el resto queda implícito, precisamente porque el lector sabe que a esa porción le acompaña un marco textual que le da vida. Por practicidad se transcribe sólo una porción. Así, si no existiera la remisión los documentos jurídicos se remitirían a los otros por trascripción íntegra. El mecanismo de la remisión y la predecibilidad de los géneros textuales jurídicos le permite al redactor omitir la reproducción de la trascripción del texto íntegro, que es lo que debiera hacer. Sin embargo, hay excepciones: un lector exigente en cuanto al cumplimiento de los requisitos de felicidad del acto jurídico como pueda ser el Notario, exige leer primero el documento relacionado como conjunto, y sólo entonces hace una remisión al mismo desde el documento básico que formaliza. Por ejemplo, en la Escritura del Notario dice del compareciente:

"El compareciente tiene la capacidad legal necesaria para otorgar el presente en virtud de Escritura Notarial de Apoderamiento formalizada por el Notario de Barcelona, D. ...., en fecha ......, y que consta en el $n^{\circ}$ de su Protocolo..........

En otras expresiones vemos que no se alude ya al documento, sino directamente al acto que éste realiza, es decir, al acto jurídico principal que muchas veces, por nominalización, designa a la institución:

“... en virtud de apoderamiento/nombramiento en Escritura Pública Notarial....”

Sin embargo, muchos de los requisitos del negocio básico no es necesario acreditarlos, sino que se presumen y, por tanto, muchas veces no existe una remisión a un documento acreditativo, sino simples manifestaciones incluidas en el documento sobre la verdad de la concurrencia de los requisitos, o ni siquiera eso. Incluso, excepcionalmente, en las Escrituras Notariales aparece lo siguiente: "Conozco al compareciente personalmente y me consta que tiene la capacidad legal necesaria para otorgar la presente Escritura Pública de ..."

Más específicamente, la remisión a los actos anteriores tiene la función de acreditar que las personas que otorgan el negocio efectivamente son "personas", (tienen personalidad jurídica), tienen la capacidad suficiente, tienen la motivación y voluntad de otorgarlo y, finalmente, tienen la titularidad sobre los derechos objeto del negocio. Se trata de cuatro aspectos que componen una situación jurídica previa.

Veamos a continuación en qué supuestos se presume y en qué supuestos se acredita la concurrencia de los requisitos, repasando los cuatro aspectos mencionados, en la situación jurídica previa y también, en su caso, la situación jurídica resultante.

La situación jurídica previa se explicita en el documento en la medida en que se considera necesario, dado que también actúan presunciones jurídicas que relevan de ello (casilla izquierda de la tabla a continuación)

También se explicita en el documento el acto jurídico modificador (progresión temática verbal) de la situación jurídica previa (casilla central) y la situación jurídica resultante, de la que tratamos en las casillas de la derecha.

En la tabla observamos cómo en cada uno de los aspectos mencionados ("la persona", "la capacidad", "la motivación o causa", y el propio acto) se percibe el transcurso, el movimiento, de la situación previa a la resultante, pasando por el acto. Así, se pasa de las circunstancias del sujeto como un ser pasivo de la situación previa, al sujeto agente; el sujeto se convierte en un "agente", 
en un ser activo en cuanto entra en actividad jurídica como otorgante del acto. Así, varía su denominación en el transcurso del texto: de Juan Casatremenda pasa a las partes contratantes, el adquirente, la parte incumplidora, etc. denominaciones éstas que contienen movimiento) y, finalmente, el sujeto aparece como estático cuando se sitúa en la situación o posición jurídica resultante: el titular del derecho, el acreedor, el propietario, etc., aunque, en ocasiones la situación jurídica resultante queda impregnada por un eco del movimiento, del acto que fue: el adquirente, el transmitente, incluso cuando ya se ha producido la parte del documento que narra la transmisión y se está describiendo el resultado. Por supuesto, en ocasiones no aparece explícitamente una tal descripción de la situación jurídica resultante.

$\begin{array}{lll}\text { Situación previa } & \text { El acto } & \text { Situación resultante }\end{array}$

\begin{tabular}{|c|c|c|}
\hline $\begin{array}{l}\text { 1. LA PERSONA } \\
\text { EXISTENCIA E IDENTIDAD } \\
\text { DE LA(S) PERSONA(S): } \\
\text { ACTO DE IDENTIFICACIÓN } \\
\text { Y ACREDITACIÓN DE LA } \\
\text { IDENTIFICACIÓN }\end{array}$ & $\begin{array}{l}\text { SUJETO AGENTE } \\
\text { DEL ACTO QUE SE } \\
\text { REALIZA }\end{array}$ & $\begin{array}{l}\text { SUJETO OBLIGADO } \\
\text { (A VECES } \\
\text { TRANSMITENTE DE } \\
\text { DOMINIO) } \\
\text { Y } \\
\text { SUJETO RECEPTOR } \\
\text { DE DERECHOS (A } \\
\text { VECES ADQUIRENTE } \\
\text { DE DOMINIO Y } \\
\text { TITULAR) }\end{array}$ \\
\hline \multicolumn{3}{|c|}{$\begin{array}{l}\text { El texto describe la situación jurídica previa mediante un acto de identificación y, en } \\
\text { su caso, de acreditación de la identificación. }\end{array}$} \\
\hline $\begin{array}{l}\text { 2. CAPACIDAD } \\
\text { ACTO ACREDITACIÓN DE } \\
\text { LA CAPACIDAD } \\
\text { DECLARACIÓN DE } \\
\text { CAPACIDAD DE LOS } \\
\text { SUJETOS OTORGANTES Y } \\
\text { REMISION AL } \\
\text { DOCUMENTO } \\
\text { ACREDITATIVO } \\
\text { (a veces incluso se adjunta el } \\
\text { poder por anexolo se exhibe al } \\
\text { fedatario para que conste por } \\
\text { testimonio, con transcripción de } \\
\text { los párrafos pertinentes) }\end{array}$ & $\begin{array}{l}\text { El acto se realiza con la } \\
\text { necesaria capacidad. }\end{array}$ & \\
\hline
\end{tabular}




\section{TITULARIDAD DE DERECHOS}

EL QUE SE OBLIGA TIENE UNAS CAPACIDADES: PERICIA, HABILITACIÓN PROFESIONAL,

VOLUNTAD REAL NEGOCIACIONES PREVIAS ACUERDO

INTENCIÓN DE VINCULARSE Y/O MODIFICAR LA REALIDAD JURÍDICA

\section{ACTO JURÍDICO MODIFICADOR}

DECLARACIÓN/ES DE VOLUNTAD EXTERNAS NO SE ACREDITA PORQUE SE PRESUME. EXCEPCIONALMENTE SE EXPLICITA QUE NO HAY VICIOS DE LA VOLUNTAD (ERROR, DOLO, VIOLENCIA O INTIMIDACIÓN)-testamento
SITUACIÓN JURÍDICA RESULTANTE

(creación derechos

de crédito-

obligación,

transmisión de

derechos,

constitución de entidades)

\section{La naturaleza de la remisión y sus fórmulas. Ejemplos}

Retomamos el contrato como ejemplo prioritario, dado que en él se suelen hacer remisiones a los actos anteriores. $^{14}$

DE UNA PARTE, D. XX, mayor de edad, casado, con domicilio en... calle... $\mathrm{n}^{\circ} \ldots$ y con D.N.I. $\mathrm{n}^{\circ}$ ... como Gerente de la Sociedad ZZ, según se desprende (nexo de la remisión) de la escritura de nombramiento (mención del documento) otorgada (mención del acto de otorgamiento) ante el Notario Don ... de ... (fedatario que formalizó el acto) en fecha ...

Declara que no han sido limitadas, modificadas o revocadas las facultades que se le confieren (acto de conferir facultades) en (nexo de la remisión) el Artículo X de los Estatutos de dicha Sociedad (documento al que se remite) que D. XX aporta (acto de prueba de las facultades mediante presentación del documento), constando dichos Estatutos en escritura de constitución de la Sociedad de fecha... otorgada ante el Notario antes citado, e inscrita en el Registro Mercantil de... Tomo... Libro... Folio ... y, (el documento dentro del documento).

\section{DE OTRA PARTE,}

D. $ـ$ mayor de edad, casado, comerciante, con domicilio en... calle... ... $\mathrm{n}^{\mathrm{o}} \ldots \mathrm{y}$ con D.N.I. $\mathrm{n}^{\mathrm{o}}$ ..., bajo el nombre comercial no registrado de AA, dedicado a la venta de ..., (...) reconociéndose mutuamente y teniendo, a juicio del Corredor de Comercio Colegiado interviniente (remisión al fedatario, en este caso, y no a un documento), la capacidad legal para el otorgamiento del presente contrato.

¿Es siempre el documento subordinado el que hace la remisión al documento básico, "más importante" (en este caso, el contrato), o, por el contrario, es el básico el que hace la remisión? Parece independiente. El criterio que determina que el uso imponga o no la remisión es facilitar la comprensión, por una parte, y acreditar, es decir, suministrar una prueba, por otra. Así, un contrato como el del ejemplo se remite al poder para acreditar la capacidad, pero el poder, que tiene una vocación de otorgar facultades al apoderado con carácter general para cualquier acto, no sólo para ese contrato concreto, no hace ninguna referencia al contrato, a menos que se confiera mediante un 
contrato de mandato de representación ${ }^{15}$ que se otorga específicamente y sólo en relación con el contrato que se otorgará.

En fin, la presencia o ausencia de la remisión obedece siempre a razones funcionales y no casuales. Además, incluso, puede que sea necesario ${ }^{16}$ que la remisión sea explícita. Por ejemplo, como hemos visto, el Notario español, por exigencias del Reglamento notarial, en ocasiones debe mencionar otros documentos (escritura de apoderamiento, por ejemplo). Por el contrario, en otros casos, la remisión basta con una remisión implícita. En un contrato privado entre empresas, los otorgantes representantes de las mismas ya se conocen y no acreditan el poder de representación en el acto de otorgamiento y mucho menos se refieren al contrato que se otorga. Dicho poder de representación se da por supuesto.

La remisión explícita suele hacerse al documento (contrato, poder, testamento), rodeado de todas las circunstancias de espacio y tiempo y aun con una especificación del acto jurídico principal (performativo), lo que permite que en todo momento el negocio jurídico aparezca como una crónica histórica de lo que sucedió. Una crónica con una gran pretensión de concreción y precisión en cuanto a los elementos históricos del documento. En el ejemplo anterior aparecen los performativos: Escritura otorgada, facultades que se confieren.

Ello permite que se realice la función de prueba que tienen los documentos jurídicos (la Escritura, los Estatutos, etc.). La prueba de los actos y situaciones jurídicas (de los requisitos de validez del negocio en este caso) es esencial a la naturaleza del derecho porque no tienen efectividad, si no pueden probarse. Y no pueden probarse si no constan de forma precisa las circunstancias de su creación.

“(...) constando dichos Estatutos en Escritura Pública de constitución de la Sociedad de fecha ..., otorgada ante el Notario de B. ... d ... , e inscrita en el registro Mercantil de .... Tomo...."

La remisión es, en sí misma, también un acto de habla. Es un acto de habla con función de remitir. Normalmente, como veremos, no se contenta con remitirse al documento, sino que alude al acto de otorgamiento, es decir, al acto de habla que se realiza. Los ejemplos a continuación nos permitirán apreciar la naturaleza de la remisión.

Son muchos los motivos/funciones jurídicas que determinan la remisión de un documento a otro y la remisión de una parte del documento a otra. Sin embargo, no nos centramos en ejemplos de remisión que meramente informan (es el caso de todas las posibles remisiones), sino en ejemplos de remisión que, al mismo tiempo, acreditan.

Los esquemas conceptuales desarrollados ${ }^{17}$ nos permiten anticipar que el encabezamiento del contrato, en cuanto contiene la identidad y características del sujeto del acto (domicilio, capacidad, etc.), ya presentará numerosas remisiones ${ }^{18}$ a los documentos relacionados, siempre que sean anteriores y guarden relación con el sujeto, acreditando su existencia (personalidad jurídica) y su capacidad. ${ }^{19}$ Después nos centraremos en el objeto.

\section{El sujeto como sujeto de derechos: la personalidad jurídica}

Así, respecto de la persona de las partes contratantes será necesario demostrar que existen y son sujetos de derecho, es decir, que tienen personalidad jurídica. La remisión no sólo informa sino que acredita:

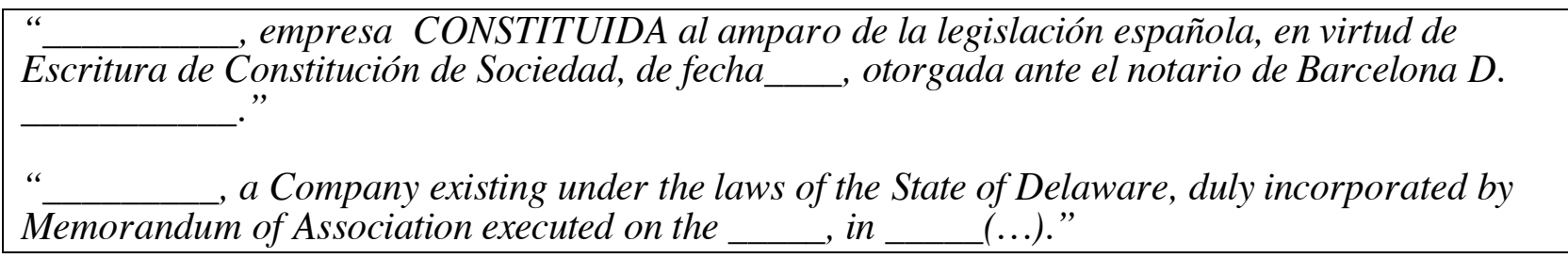


Las expresiones anteriores incluyen una remisión al ordenamiento jurídico que regula y da vida a la persona como sujeto de derechos: al amparo de la legislación española, under the laws of the State of Delaware.

Vemos igualmente que existe una remisión al documento que vehicula la creación de la persona jurídica (escritura de Constitución de Sociedad, Memorandum of Association). El documento referido emana de un acto voluntario (constitución de sociedad/incorporation of a company) y constan las circunstancias de su otorgamiento.

Constituida en virtud de Escritura de Constitución de Sociedad, de fecha otorgada ante el notario de Barcelona $D$.

duly incorporated by Memorandum of Association executed on the in

Como siempre, la virtualidad jurídica del acto, en este caso, el acto de creación o constitución de la persona jurídica, se expresa mediante el nexo: en virtud de. Si la persona jurídica existe es porque el acto de creación tiene la virtud de producir efectos jurídicos.

\section{La capacidad de obrar}

La capacidad de obrar, es decir, la capacidad de realizar un acto concreto, debe acreditarse, en la mayoría de los casos, bien por disposición expresa de la ley, bien porque así lo exige el uso y la naturaleza de las cosas, pues no suele presumirse. Así, por ejemplo, el que actúa en nombre propio deberá acreditar su capacidad mediante la presentación del D.N.I., por ejemplo, que mostrará su edad. Así, por ejemplo, en el testamento notarial, el notario exige al otorgante que muestre su carnet de identidad. Ello le permite comprobar no sólo la identidad del mismo, sino también su capacidad, es decir, que tiene más de 14 años, conforme al artículo 662 del Código Civil español. Cuando actúa en nombre de otro, es necesario que pruebe su capacidad o facultad de representación mostrando los poderes de representación. Nos referimos a este supuesto a continuación.

Los poderes de representación son necesarios para que el que comparece pueda acreditar la representación con que actúa. Como en el caso anterior, la remisión no sólo informa sino que acredita. Muchas veces el apoderado muestra el documento de apoderamiento y lo retira, a fin de probar que tiene la capacidad necesaria.

(...) en virtud de poderes que exhibe y retira, manifestando que no le han sido revocados ni disminuidos.

(...) según se desprende de la escritura de nombramiento otorgada ante el Notario Don ... de ... en fecha ... y ...

En los ejemplos anteriores vemos una alusión al documento (poderes, escritura de nombramiento).

Actúa habiendo sido debidamente facultado ${ }^{20}$

\section{Contraste entre remisión implícita y explícita}

Ilustramos a continuación la remisión implícita o tácita, extraída de dos contratos de licencia mercantil, uno en castellano y el otro en inglés. En el ejemplo en inglés sólo aparece el nombre de los representantes y la calidad con la que actúan en el momento de la firma: 
REUNIDOS:

DE UNA PARTE

DE OTRA PARTE en calidad de representante de Productions Ltd. (...) en calidad de representante de ESPECTACLES S.L. (...)

THIS AGREEMENT is entered into and effective as of this day of 1995 (the "Effective Date") by and between LICENSOR Inc. doing business in Simi Valley, California. LICENSORINC. is a corporation residing at ___ Agate Ct., Valley...... (the LICENSOR) Y of business at ("LINCENSEE") having its principal place

IN WITNESS WHEREOF, the parties have caused this agreement to be signed by their duly designated and authorized representatives.

Son dos ejemplos de remisión implícita porque, aunque se habla del título o condición con que actúan las partes otorgantes (ambas lo hacen en calidad de representantes), no se hace remisión al documento de apoderamiento que los ha convertido en representantes.

La predictibilidad de los géneros textuales jurídicos permite al redactor omitir la trascripción del documento relacionado y ahorrarse, por esa misma razón, la remisión de forma explícita. La remisión es implícita gracias a ese marco legal estable que el ordenamiento presta al documento y gracias a las consiguientes convenciones textuales.

Por el contrario, en los siguientes ejemplos se observa una remisión explícita:

De una parte, D...............quien actúa en su calidad de Administrador único de la Sociedad Anónima............. en virtud de (nexo de la remisión) poderes (alusión al tipo de documento) que exhibe y retira (actos relacionados con el documento en cuestión), manifestando que no le han sido revocados ni disminuidos.

Ambas partes se reconocen la mutua capacidad necesaria para la firma del presente contrato, y puestos previamente de acuerdo,

En el ejemplo a continuación comprobamos los mismos elementos: nexo de la remisión/mención del documento/mención del acto de otorgamiento del documento.

DE UNA PARTE, D. XX, mayor de edad, casado, con domicilio en ... calle $\ldots \mathrm{n}^{\mathrm{o}} \ldots \mathrm{y}$ con D.N.I. $\mathrm{n}^{\circ}$ ... como Gerente de la Sociedad ZZ, según se desprende (nexo de la remisión) de la escritura de nombramiento (mención del documento) otorgada (mención del acto de otorgamiento) ante el Notario Don ... de ... (fedatario que formalizó el acto) en fecha (circunstancias espaciotemporales del otorgamiento).

Declara que no han sido limitadas, modificadas o revocadas las facultades que se le confieren (acto de conferir facultades) en (nexo de la remisión) el Artículo X de los Estatutos de dicha Sociedad (documento al que se remite) que D. XX aporta (acto de prueba de las facultades mediante presentación del documento) constando dichos Estatutos en escritura de constitución de la Sociedad de fecha ... otorgada ante el Notario antes citado, e inscrita en el Registro Mercantil de ... Tomo ... Libro ... Folio ... y, (circunstancias espaciotemporales del otorgamiento). 


\section{DE OTRA PARTE,}

D.___ mayor de edad, casado, comerciante (no hay una remisión al título de habilitación profesional), con domicilio en ..., calle ... $\mathrm{n}^{\circ}$... y con D.N.I. $\mathrm{n}^{\circ}$...(remisión al documento de identificación), bajo el nombre comercial no registrado de AA, dedicado a la venta de ..., reconociéndose mutuamente y teniendo, a juicio del Corredor de Comercio Colegiado interviniente (remisión al fedatario en este caso y no a un documento), la capacidad legal para el otorgamiento del presente contrato.

\section{El objeto}

Igualmente, la transmisión de derechos exigirá acreditar que el transmitente efectivamente es titular de los derechos.

Ostenta el derecho de propiedad sobre la finca en virtud de (nexo de remisión) escritura de compraventa (documento relacionado-probatorio del título de propiedad) celebrada (performativo correspondiente al documento relacionado) en Barcelona ante el Notario de Barcelona, D.........en fecha de......., $\mathrm{n}^{\mathrm{o}}$ de Protocolo..... (circunstancias históricas de la emisión del documento relacionado).

(Por otra parte, suele existir una remisión intratextual para realizar la descripción del producto o del inmueble que se vende $)^{21}$.

\section{Conclusión: alcance del intertexto y de la remisión}

Tras situar el documento básico en el seno de la cadena, entre los documentos preparatarios y los ejecutivos, concluimos:

Que existe siempre un nexo o remisión causal entre los documentos (excepto en el caso de los negocios abstractos).

Que es posible acudir a la regulación del ordenamiento jurídico así como al uso para establecer qué documentos (preparatorios o ejecutivos) se relacionan con él. Hemos proporcionado dos ejemplos: el testamento y el contrato. Se observa que los documentos relacionados se pueden categorizar en función de los requisitos de validez del negocio y de los presupuestos para su efectividad. Así, hemos estudiado, a modo de ejemplo, los documentos preparatorios en relación con los siguientes requisitos de validez: la personalidad, la capacidad y la titularidad de los derechos. Finalmente, observar las remisiones en relación con los distintos aspectos del negocio nos ha permitido establer que la presencia o ausencia de la remisión obedece siempre a razones funcionales y no casuales. Además, incluso, puede que sea necesario que la remisión sea explícita por disposición de la ley. Por el contrario, en otros casos, basta con una remisión implícita. La remisión explícita suele hacerse al documento (contrato, poder, testamento), rodeado de todas las circunstancias de espacio y tiempo y aun con una especificación del acto jurídico principal (performativo), lo que permite que en todo momento el negocio jurídico aparezca como una crónica histórica de lo que sucedió. Ello permite que se realice la función de prueba que tienen los documentos jurídicos (la Escritura, los Estatutos, etc.). La prueba de los actos y situaciones jurídicas (de los requisitos de validez del negocio en este caso) es esencial a la naturaleza del derecho porque no tienen efectividad si no pueden probarse. Y no pueden probarse si no constan de forma precisa las circunstancias de su creación. La remisión es, en sí misma, también un acto de habla función de remitir bien para informar o probar, que normalmente no se contenta con remitirse al documento, sino que alude al acto de otorgamiento, es decir, al acto de habla que se realiza.

La remisión se caracteriza porque precisamente no lo incluye todo basta con la mención del documento/performativo principal para que se produzca una evocación de todo lo que éste comporta, 
que funciona como un macroacto de habla con lazos o puentes a los distintos documentos que lo respaldan.

\section{NOTAS}

1. Establecemos que los negocios mencionados son básicos porque no están subordinados a otros de los que dependan. Sólo rinden pleitesía a la ley, que los regula.

2. Recordemos que esta relación de subordinación o dependencia recíproca de los documentos se produce precisamente gracias a la diferenciación de un documento respecto de otro, en tanto que separado e independiente el uno del otro.

3. En el sentido en que la doctrina jurídica habla de la "causa" como consecuencia del artículo 1277 del Código Civil Español que establece que todo contrato requiere una causa.

4. Con el término contrato abstracto se quiere significar que la causa carece de relevancia jurídica, es decir, que su contenido, así como los defectos de los que pueda adolecer, no trascienden al negocio (Uría 1995).

5. Parte de la doctrina considera que aunque los títulos valores funcionen en el tráfico con independencia del negocio que les dio origen, ello no los convierte en negocios abstractos, sino que se trata de negocios causales que no son oponibles frente a terceros: nuestro ordenamiento, como hemos expuesto, se inspira en un principio causalista que se manifiesta en la exigencia de que todo contrato requiere una causa, aunque ésta se presuma como dice el 1277 del Código Civil Español; por ello, no se puede admitir la categoría de los negocios abstractos, a pesar de que algunos autores defienden la abstracción de determinados contratos como sería el negocio de apoderamiento, arrendamiento de servicios, el contrato de sociedad, o los títulos valores; pero, realmente, éstos casos responden a supuestos de contratos coligados, cuyos efectos se desvinculan cuando intervienen terceros ajenos al negocio causal, nunca entre las partes.

6. Los títulos ejecutivos se caracterizan porque gozan del privilegio de la ejecución inmediata por parte del juez, sin perjuicio de que, ulteriormente, en un juicio declarativo, se impugne la validez o ejecución de dicho título.

7. Transmisión hereditaria.

8. El código se refiere a ellos en el capítulo sobre interpretación cuando considera que un elemento que tener en cuenta son los actos anteriores y posteriores de las partes.

9. En este sentido Burnham (1993:11) habla de los contratos de adhesión: "One party presents the other with a prepared document for signature. This type of agreement is often known as a "contract of adhesion" for the party in the weaker bargaining position is unable meaningfully to bargain for better terms. Under the objective view of assent, a party who neither reads nor understands the agreement is nevertheless bound by it. In this situation, the drafter for the party in the stronger bargaining position appears to be free to impose terms on the other party. Nevertheless, when planning the transaction, the drafter still faces a form of negotiation - the possibility that the law will not enforce the contract."

10. Lozano Irueste (2001) proporciona equivalencias del término acknowledgement en este contexto y de las colocaciones correspondientes: "Acknowledgement: (Com) Confirmación. Certificate of acknowledgement. Acknowledgement of order: acuse de recibo de pedido (por el proveedor/vendedor).

11. Además de la mención de la consideration, es necesario que efectivamente exista. Los contratos en que no media contraprestación (consideration), conforme a la Common-Law, son nulos. Esta doctrina ha quedado atemperada por soluciones que tratan de suavizar la exigencia del requisito de la consideration. Así, se presume la existencia de la contraprestación, por ejemplo, del precio, si el contrato de compraventa se otorga mediante un documento solemne (deed).

12. En la cláusula 1 a que se refiere esta cláusula 2 se hace referencia a "drawing under the letter of credit", que es una forma más concreta de referirse al acto de entrega del dinero prestado por el prestamista. Por supuesto, en un contrato de disponibilidad crediticia, el prestamista realiza la entrega del dinero a instancias del prestatario cuando éste retira activamente el dinero depositado en el banco. En consecuencia, más propiamente debería hablarse de entrega de dinero. Efectivamente: en el 1740 y siguientes del Código Civil Español sólo se habla de entrega y devolución. Así el 1753 dice: "El que recibe en préstamo...está obligado a devolver... Y el 1754 dice: La obligación del que toma dinero a préstamo...

13. En derecho sólo podemos decir que todo el documento es relevante, dado que se interpreta como conjunto.

14. No tanto en el caso del testamento, donde es bastante excepcional que el causante haga una descripción de la situación jurídica de su patrimonio. Si es así, suele haber una remisión a los títulos de propiedad y al lugar en que se encuentran, sobre todo en los testamentos más antiguos.

15. Que contiene, de hecho, un apoderamiento. 
16. Por mandato de la ley o, de conformidad con el derecho voluntario, para que se produzca el efecto deseado.

17. Actos anteriores y posteriores. Sujeto, objeto y causa, etc.

18. Igualmente, la legitimación y licitud del objeto y de la titularidad sobre el mismo puede conllevar remisiones a actos o circunstancias previas

19. La distinción entre personalidad jurídica y capacidad de obrar está regulada en el propio Código Civil español. El artículo 29 establece: "El nacimiento determina la personalidad" (Art. 29). "La personalidad civil se extingue por la muerte de las personas". Por su parte y, ya en relación con las personas jurídicas, que, por tanto también tienen personalidad jurídica, el Artículo 35 establece lo siguiente: Son personas jurídicas: Las corporaciones, asociaciones y fundaciones (... ). Su personalidad empieza desde el instante mismo en que, con arreglo a derecho, hubiesen quedado válidamente constituidas. El artículo 38 establece el alcance de su personalidad como sujetos de derecho: "Las personas jurídicas pueden adquirir y poseer bienes de todas clases, así como contraer obligaciones y ejercitar acciones civiles o criminales conforme a las leyes y reglas de su constitución." Por otra parte, en todo el código aparece la capacidad de obrar en relación con los distintos actos. Por ejemplo, para el testamento los artículos 662 y 663 regulan esta materia: Art 662: "Pueden testar todos aquellos a quienes la ley no lo prohíbe expresamente.” Y, el Art. 663 establece: "Están capacitados para testar: $1^{\circ}$ Los menores de catorce años de uno y otro sexo; $2^{\circ} \mathrm{El}$ que habitual o accidentalmente no se hallare en su cabal juicio."

20. Facultado deriva de facultar.

21. La remisión intratextual de la que no nos ocupamos utiliza el mismo procedimiento de alusión al documento, incluso para expresar que los actos que se realizan en el documento son eficaces: En virtud del presente; en virtud del presente contrato; en virtud de lo dicho en ...; en virtud de lo pactado en la cláusulaIgualmente la remisión a la ley como fuente de eficacia jurídica se produce mediante expresiones similares: En virtud del artículo...de la ley..; actúa en virtud de las facultades que le otorga la ley...En otras expresiones vemos que no se alude ya al documento, sino directamente al acto que éste realiza, es decir, al acto jurídico principal que muchas veces, por nominalización, designa a la institución.

\section{REFERENCIAS BIBLIOGRÁFICAS}

BEAUGRANDE, R. y W. DRESSLER (1997): Introducción a la lingüística del texto, Barcelona, Ariel.

BORJA, A. (1998): Estudio descriptivo de la traducción jurídica : un enfoque discursivo, Barcelona, Facultat de Traducció i Interpretació, Universitat Autònoma de Barcelona, Tesis doctoral.

BORJA, A. (2000): El texto jurídico inglés y su traducción al español, Barcelona, Ariel.

ChILD, B. (1988 y 1992): Drafting legal documents. Materials and problems, St. Paul, West Publishing co.

De Castro y Bravo, F. (1949): Derecho civil de España, Madrid, Civitas.

DieZ, L. y A. Gullón (1992): Sistema de derecho civil, Madrid, Tecnos.

Flume, W. (1998): El Negocio Jurídico, Madrid, Fundación Cultural del Notariado.

FERRÀN, E. (2002): Las funciones jurilingüísticas en el documento negocial. Un enfoque pragmático, Universitat Autónoma de Barcelona, Tesis Doctoral. 